\title{
Effectiveness of family training and life skills on caring chronic mental disorders in an Iranian population
}

\author{
Hassan Azargoon, Maryam Akbari Motlaq* and Mohsen Dareke \\ Payamenoor University, Neishabour, Iran.
}

(Received November 13, 2012; Accepted March 15, 2013)

\begin{abstract}
This research is semi-empirical study which is done to examining the effectiveness of family trainings and life skills on Caring Chronic Mental Disorders in Mashhad (Iran). 300 participants has been chosen in randomly from the families of chronic mental disorders who has been admitted in round the clock centers in Mashhad and who had been in waiting list and these participants has been divided to two groups of experiment and control randomly and we introduce family trainings and life skills to experiment group. There was no training to control group. These two groups were tested period to the beginning of trainings and post training with instruments such as California Social Adjustment Questionnaire; Families' Attitude and Awareness about Life Skills and Family Trainings; Rosenberg Self-Esteem; General Health Questionnaire; and Symptom Checklist-90-Revised. Results indicated that training had no effect on the attitude of families toward taking care of mental disorder, but family member's attitude toward mental disorder has been changed. This training has been influential on changing family member's attitude toward life skills, social adjustment, self esteem, mental health increase and reducing mental disorders.
\end{abstract}

Keywords: family, life skills, chronic mental disorders.

Efectividad de un entrenamiento familiar y de la habilidades de la vida en el cudidad de pacientes crónicos con enfermedad mental en una población iraní.

RESUMEN:La presente investigación es un estudio cuasi-experimental para evaluar la efectividad de un entrenamiento en habilidades en el cuidado del trastorno mental grave en Mashhad (Irán). 300 participantes han sido seleccionados de forma aleatoria entre los familiares de trastornos mentales crónicos admitidos en los centros de Mashhad y que había estado en la lista de espera. Estos participantes han sido divididos en dos grupos, experimental y control, introduciendo el entrenamiento en familia y de habilidades para la vida en el grupo experimental. No hubo ningún entrenamiento en el grupo control. Estos dos grupos fueron evaluados al inicio y final del entrenamiento con instrumentos como el Cuestionario de Ajuste Social de California, Actitud de las Familias y Reconocimiento sobre Habilidades de la Vida y Entrenamiento Familiar; Autoestima de Rosenberg; Cuestionario General de Salud; y Listado de 90 Síntomas Revisado. Los resultados indicaron que el entrenamiento no tuvo efecto en la actitud de las familias sobre el cuidado de los trastornos mentales, pero la actitud hacia la enfermedad 
mental ha cambiado. Este entrenamiento ha sido muy influyente en el cambio familiar en las actitudes hacia las habilidades de la vida, el ajuste social, autoestima, el incremento de la salud mental y la reducción de los trastornos mentales. Palabras clave: familia, habilidades de la vida, trastorno mental crónico.

\section{INTRODUCTION}

Family is semi-organized systems which plays the role of internal communication and possess members who have acquired different positions and places and perform its roles according to the content of the role, positions, thought, and kinship relationships. One of the main duties of families is providing a suitable environment for nurturing family members and supplying security and mental and physical hygiene for all the family members. Psychological and educational commentators consider family organization as the most important institution in nurturing and human behavior and consider family environment as the basic and most enduring factor in the personality genesis of human and the laying plot for their physical, moral, social, rational and affective development. (Goodstein \& Lanyon, 2005)

This belief that family members gain much of their characteristics from learning experiences in family is one of the obvious findings of today's thought. So is this belief that problematic families nurture problematic people. The main assumption is that behavioral and emotional problems are due to structural characteristics of families, so any change in undesirable structure of families which continues these problems can be effective in changing subject's symptoms. (Minuchine, 1989; Mackie \& Smith, 2000)

The belief that social problems are related to family function and so we can (according to this function in society) correct them goes back to at least 18th century. However this point is interesting that formal theory and research about the possible role of family in the development of anomy has been proposed recently in psychology and psychiatry literature. In fact, development of the systematic paradigm of family function and its effects on its members has not been revealed by mid twenty century. (Lasiter, 2005)

After the decline of psychopathic theories, an alternative approach which emphasized on family system (as a single general system) emerged at the end of 1950 and 1960. At these years the attention focus of clinical experts and theorists went toward human communication dynamics with specific attention to schizophrenia. After that, systemic paradigm and family was proposed as a transformed system by Minuchine (Kahn, 1989).

Findings of Minuchine's studies (1981, cited by Tozandehjani and Seddighi, 2006), Graham and Cockreil (2004), Greenberg (2001), Johnson and Smith (2006) indicate that emotional and behavioral problems are due to family structural characteristics and so any change in undesirable structure of family which continues these problems, can be effective in changing patient's symptoms.

Campbell et al (2006) studies indicate that family is a cybernetic system 
in which each member's behavior is related to each individual's equal system functionally and so their rupture is not so important.

In recent years, this belief has been proposed that family processes are related with creation and maintenance of family members' mental and behavioral disorder. The main point is that family members' behavior is related functionally to the environment that family provides for their nurturing. Almost all schools of thought agree on this belief that peoples' behavior is related to their family environment functionally (Sanders \& Dadci, 2003; cited by Noori, 2004)

McGrath and Bronstein (2007) has done a study named "examining the performance of schizophrenia families and their non-schizophrenia counterparts" and found that there is a significant difference between general performance of families and their elements (problem solving, communication, roles, affective assistance, affective association and behavior control) in schizophrenic patients and non schizophrenic counterparts.

Elias (2007) believes about family training that hygiene training means communicating with people and social groups with the aim of positive health development and eroding disease through influencing and changing people's attitude, beliefs and behavior.

Promoting family members' awareness level, changing their attitude toward mental disorder patients, promoting social adjustment level and self esteem of family members and specially their parents, teaching life skills, promoting family members' temperament and so on, can be effective in controlling and caring chronic mental disorder patients in family (Carver et al., 2003;2004)

Studies carried on by Sanders and Dadci (1993) indicate the role of coherent processes of family interaction on family members' pathology.

Researches indicate that in the family as a systematic, structural and dynamic system, behavior of each member is related to equal systems of each family member functionally and the rupture of this relationships isn't so important (cited by Florsheim, 2003).

Brogan (1985) considers health promotion and disease prevention parts of general health concept (cited by Teri, 2003).

MoosaviShooshtari (2006) did a research named "examining the relationship between family performance with mental conditions in peculiar patients" and found that family performance influences mental condition in peculiar patients.

World Health Organization (1999) has done a study entitled "family training protocol: a fundamental step towards promoting mental hygiene and family health" and found that family health is important in three period: (1) pre marriage consultations, (2) organizing successful and agreeable marital communications, and (3) child training.

Khayati (1996) has done a study by the name of "examining the effects of life skills training on self-esteem and found that life skills training can result in more self esteem.

FalsafiNezhad (1993), Pahlavanzadeh et al. (1998) has done a study with the title of "the effects of life skills training on students' mental health" and found 
that life skills training can result in mental health promotion, anxiety reduction, depression reduction and students' social function promotion.

Family and environmental hygiene is one of the subjects which is taught for parents in family training courses and the significance of this subject in family training courses is because of necessity of providing a familial and social environment conforming to physical and mental hygiene principles for a healthful and constructive life for the parents and their children. This issue is more important in the families which have chronic patients. (Kata \& Joiner.2002)

Just as hygiene is the responsibility of medicine and its duty is very important and physical health of the people is related to it, hygiene and mental health of the citizens has gain importance for experts and authorities and they consider training as the main path to mental health promotion.

In this study, researchers are going to examine this issue that: Are family training(for example training skills such as negative temperament, controlling and reducing cognitive errors, gender roles, conflict resolving, financial management) and life skills training (for example training skills such as creative thinking, critical thinking, decision making skills, problem solving, stress control, anger control and communicative skills) effective in family members' attitude and awareness in caring for chronic mental patients in the family or not? In other words are these trainings effective in social compatibility level, self esteem, general health promotion and reducing mental disorder in influential family members which have patients with chronic mental problems?

\section{METHOD}

\section{Participants}

The sample society consists of 190 participants. They voluntarily participated in this study. All of them were female. The mean age of the participants was 34.63 years $(\mathrm{SD}=2.56)$.

This research is a semi-empirical type of researches which is done with the aim of examining the effects of family trainings and life skills training on the family with chronic mental disorder patients on their taking care of these patients in the family in Mashhad. Statistical population of this research is all the families of male and female chronic mental disorders who have been admitted in round the clock and daily centers and also families of chronic mental disorders in waiting list (nearly 2800 families).

The sample includes 300 families (influential family members). In experimental group, 75 families were selected stratified randomly from families of chronic mental disorders admitted in round the clock and daily centers of Samen, Atef, Ghaem, Hasti, and Tous centers(Mashhad, Iran), and 75 families are selected systematic randomly from enrolled families in waiting list. Another 150 families were selected systematic randomly from enrolled families in waiting list as control group. This group received no training. It should be noted that 
selected subjects were influential family members and mainly family protector, but because of research limitations and other reasons, experiment group reduced to 80 and control group to 110 .

\section{Procedure}

The experimental group received one and half hours of family training and life skills training in 12 sessions, three sessions a week for a month. Another 150 families were on a waiting list as control group. Participants in the control group have no training in this period. Participants voluntarily participated in this training and the training was conducted by a clinical expert. In general, the various aspects of this research were evaluated by five questionnaire. All participants were asked to complete questionnaires before and at the end of the training course.

Family training and life skills training incorporate age-appropriate and culturally relevant information, facilitated discussion, and structured activities in 12 class sessions across 1 month. After meeting and informed of the meeting, the following information was presented through training sessions and participants' questions were answered.

Self-awareness and empathy skills (skills to deal with emotions and different ways to create harmony with others to create an empathic relationship). Skills to cope with stress, and be familiar with the warning signs of mental and behavioral, beneficial trainings for stress relief, (Such as relaxation, mental imagery and deep breathing). Personal relations and interpersonal skills (explain the nature of the relationship and communication barriers, speaking and listening skills and nonverbal skills with using role play). Creative and critical thinking (Introductory special features cause a creative thinking), Decision-making skills, Problem solving skills (Discuss issues and solve problems effectively confront or cope with it).

\section{Instruments}

In general, different dimensions which are examined in this research are measured by five tests and questionnaires:

1. California Social Adjustment Questionnaire (Schludermann\& Schludermann, 2000). This test measures a person's personal and social adjustment profile and includes 180 questions and 12 scales. Internal consistency by test splitting for social adjustment sub-tests has been reported from $\alpha=.87$ to $\alpha=$ 90. Coefficient $\alpha$ of total test was .87 .

2. Rosenberg Self-Esteem (Rosenberg, 1965). This 10- item scale assesses an individual feelings of self-worth when the individual comparers himself or herself to other people. Reliability by Test- Retest was .82 to .85 and criterion validity was .55 .

3. General Health Questionnaire (GHQ) (Williams\& Goldberg, 1976). The most common assessment of mental well-being is the GHQ. Developed as 
a screening tool to detect those likely to have or be at risk of developing psychiatric disorders. Reliability coefficients have ranged from .78 to .95 in various studies. The average sensitivity equal to the questionnaire was .84 and equal to the average characteristics was .82 .

4. Symptom Checklist-90-Revised (SCL-90-R) (Derogatis, 1983). This is a 90 questionnaire test to assess psychiatric symptoms. This test can be used to distinguish healthy subjects from patients. There is strong support for its validity and its suggested dimensionality. Coefficient $\alpha$ ranged from .77 to 90 .

5. Families' Attitude and Awareness about Life Skills and Family Trainings: This questionnaire was made by the first author of this article, it is a questionnaire designed specifically for this research and it has 30 items based on Likert attitude test. Cronbach's alpha was used to determine the reliability of this questionnaire. Reliability of questions was approved with $\alpha=.70$. Content validity was used to determine the validity of test. To this end, questionnaires were given to 10 chosen experts and Its content validity was assessed. Each reviewer independently rated the relevance of each item on this questionnaire. To the conceptual framework using a 4 point Likert scale( $1=$ not relevant, $2=$ somewhat relevant, $3=$ relevant, $4=$ very relevant). The content validity index(CVI) was used to estimate the validity of the items(Lynn, 1996). The results of the validity testing indicated it is an accurate measure of Attitude and Awareness about Life Skills and Family Trainings. Also, the clarity of the wording, likelihood the target audience would be able to answer the questions, and the layout and the style were appropriate.

\section{RESULTS}

In this research, descriptive statistics indices are used for examining and describing demographic characteristics of subjects (in both experiment and control groups) and inferential statistics indices such as t-test in independent groups, Chisquare test, variance analysis test(F) and Shefe and Toki pursuit test are used for inferential analysis of data. Above analyses were done with SPSS- 16 software.

According to first hypothesis: family and life skills trainings are influential on family members attitudes towards caring mental disorder patients in the family. For testing this hypothesis in both experiment and control groups, t-test is used in independent group and then in dependant groups in Families' Attitude and Awareness about Life Skills and Family Trainings (table 1).

Table1. T-Test Result in Independent Groups In Order tTo Comparing Means in Experimental and Control Group in Attitude of Caring Mental Illness in Family

\begin{tabular}{|c|c|c|c|c|c|c|}
\hline \multirow{2}{*}{$\begin{array}{c}\text { Variables } \\
\text { Groups }\end{array}$} & \multirow{2}{*}{ numbers } & \multirow{2}{*}{ Means } & \multirow{2}{*}{$\begin{array}{c}\text { Standard } \\
\text { deviation }\end{array}$} & \multicolumn{3}{|c|}{$\mathrm{t}$ - test } \\
\cline { 5 - 7 } & & & $\mathrm{t}$ & $\mathrm{df}$ & $\mathrm{p}$ \\
\hline Experimental group & 80 & -.450 & 8.23 & -.949 & 188 & .344 \\
\hline Control group & 110 & .450 & 6.23 & & & \\
\hline
\end{tabular}


As absolute value of $t$ calculated with degree of freedom of $188(t=.949)$ is less than $\mathrm{t}$ standard $(\mathrm{t}=1.980)$, so null hypothesis is confirmed. So we conclude with $95 \%$ confidence that difference in averages of two control and experiment groups in attitude test toward caring patients in family is not confirmed.

According to information gathered and because of insignificant differences between averages, we conclude that researcher's claim about "difference in family attitudes toward caring mental disorder patients in family "is not confirmed. In other word, family and life skills trainings do not result in differences in both control and experiment group in respect to caring patients in family. Differences in averages of pre- and post tests of control and experiment groups in attitude test toward caring chronic mental disorder patients in family is not significant.

We used our researcher made questionnaire(Families' Attitude and Awareness about Life Skills and Family Trainings) For testing second hypothesis of this study "the effect of family and life skills on attitude, awareness and knowledge of family members about life skills" in both control and experimental group, ttest in independent groups and then in dependant groups (table 2).

Table 2. T-Test Result in Independent Groups in Order to Comparing Means in Experimental and Control Group in Attitude of Family to Life Strategies

\begin{tabular}{|c|c|c|c|c|c|c|}
\hline \multirow{2}{*}{$\begin{array}{c}\text { Variables } \\
\text { Groups }\end{array}$} & \multirow{2}{*}{ numbers } & \multirow{2}{*}{ Means } & \multirow{2}{*}{$\begin{array}{c}\text { Standard } \\
\text { deviation }\end{array}$} & \multicolumn{4}{|c|}{$\mathrm{t}$ - test } \\
\cline { 5 - 7 } & & & $\mathrm{df}$ & $\mathrm{p}$ \\
\hline Experimental group & 80 & -12.19 & 28.55 & -5.193 & 188 & .000 \\
\hline Control group & 110 & -1.37 & 25.28 & & & \\
\hline
\end{tabular}

As $t$ absolute value calculated by degree of freedom of $188(\mathrm{t}=5.193)$ is bigger than standard $\mathrm{t}(\mathrm{t}=1.980)$, so null hypothesis is not confirmed. So we conclude with $95 \%$ confidence that "average differences of both control and experiment groups in test of family attitude toward life skills "isn't confirmed.

According to information gathered and because of significant differences between averages, we conclude that researcher's claim about "difference in family attitudes toward life skills" is confirmed. In other words, family and life skills training have made differences in both control and experiment's attitude. Average differences in pre- and post test of experiment group has been significant but not in control group.

Table 3. T- Test Result in Independent Groups in Order to Comparing Means in Experimental and Control Group in Attitude of Family Test to Mental Illness

\begin{tabular}{|c|c|c|c|c|c|c|}
\hline Variables & \multirow{2}{*}{$\begin{array}{c}\text { Groups } \\
\text { numbers }\end{array}$} & \multirow{2}{*}{ Means } & \multirow{2}{*}{$\begin{array}{c}\text { Standard } \\
\text { deviation }\end{array}$} & \multicolumn{4}{|c|}{$\mathrm{t}$ - test } \\
\cline { 5 - 7 } & & & $\mathrm{df}$ & $\mathrm{p}$ \\
\hline Experimental group & 80 & -3.959 & 11.72 & -2.47 & 188 & .015 \\
\hline Control group & 110 & .202 & 4.81 & & & \\
\hline
\end{tabular}


Examinations related to third hypothesis of research that is " the effect of family and life skills trainings on family members' attitude toward chronic mental disorders in family, indicates that as $t$ absolute value calculated with degree of freedom of $188(t=-2.47)$ is bigger than standard $t(t-1.980)$, so null hypothesis is not confirmed. So we conclude with $95 \%$ of confidence that "average differences of both control and experimental in attitude test toward chronic mental disorder in family" isn't confirmed.

According to information gathered and because of significant differences between averages, we conclude that researcher's claim about "difference in family attitudes toward chronic mental disorders "is confirmed. Family and life skills training have made significant differences in family members' attitude toward chronic mental disorders. This difference in pre- and post test of experiment group is significant but not in control group.

Examination of fourth hypothesis, that is "effect of family and life skills training on family influential members' social adjustment" in both control and experiment groups is done by California social adjustment test (table 4).

Table 4. T- Test Result in Independent Groups in Order to Comparing Means in Experimental and Control Group in Social Adjustment Test (Total Score)

\begin{tabular}{|c|c|c|c|c|c|c|}
\hline \multirow{2}{*}{$\begin{array}{l}\text { Variables } \\
\text { Groups }\end{array}$} & \multirow{2}{*}{ numbers } & \multirow{2}{*}{ Means } & \multirow{2}{*}{$\begin{array}{l}\text { Standard } \\
\text { deviation }\end{array}$} & \multicolumn{3}{|c|}{$\mathrm{t}$ - test } \\
\hline & & & & $\mathrm{t}$ & df & $\mathrm{p}$ \\
\hline Experimental group & 80 & $\begin{array}{c}-.28 .8 \\
1 \\
\end{array}$ & 11.19 & 16.54 & 188 & .000 \\
\hline Control group & 110 & -.68 & 11.84 & & & \\
\hline
\end{tabular}

As $t$ absolute value calculated by degree of freedom of $188(t=16.54)$ is bigger than standard $\mathrm{t}(\mathrm{t}=1.980)$, so null hypothesis is not confirmed. So we conclude with $95 \%$ confidence that "average differences of both control and experiment groups in test of California social adjustment (total scale point) "is confirmed.

According to information gathered and because of significant differences between averages, we conclude that researcher's claim about "difference in the rate of social adjustment (total scale point) "is confirmed and these two groups have significant differences in this respect. In general family and life skills training have significant effects on social adjustment of influential family members (total scale point and all the sub tests of this scale). This difference in pre- and post test of experiment group is significant but not in control group.

Table 5. T- Test Resultt in Independent Groups in Order to Comparing Means in Experimental and Control Group in Self Esteem Test

\begin{tabular}{|c|c|c|c|c|c|c|}
\hline \multirow{2}{*}{$\begin{array}{c}\text { Variables } \\
\text { Groups }\end{array}$} & \multirow[t]{2}{*}{ numbers } & \multirow[t]{2}{*}{ Means } & \multirow{2}{*}{$\begin{array}{l}\text { Standard } \\
\text { deviation }\end{array}$} & \multicolumn{3}{|c|}{$\mathrm{t}$ - test } \\
\hline & & & & $\mathrm{t}$ & df & $\mathrm{p}$ \\
\hline Experimental group & 80 & -6.61 & 4.50 & 12.92 & 188 & .000 \\
\hline Control group & 110 & .78 & 3.39 & & & \\
\hline
\end{tabular}

(C) Psy, Soc, \& Educ, 2013, Vol.5, No1 
According to fifth hypothesis of the research, "family and life skills training have effects on family influential members' self esteem."As t absolute value calculated by degree of freedom of $188(\mathrm{t}=12.92)$ is bigger than standard $\mathrm{t}(\mathrm{t}=1.980)$, so null hypothesis is not confirmed. So we conclude with $95 \%$ confidence that "average differences of both control and experiment groups in test of Rosenberg self esteem test "is confirmed (table 5).

According to information gathered and because of significant differences between averages, we conclude that researcher's claim about "difference in the rate of social self esteem in both control and experiment groups "is confirmed. This difference in pre- test and post test of Rosenberg self esteem scale is significant in experiment group but not in control group.

Examination of sixth hypothesis, that is "effect of family and life skills training on family influential members' general health" in both control and experiment groups is done by general health test (table 6).

Table 6. T- Test Result in Independent Groups in Order to Comparing Means in Experimental and Control Group in Mental Health Test (GHQ)

\begin{tabular}{|c|c|c|c|c|c|c|}
\hline Variables & \multirow{2}{*}{$\begin{array}{c}\text { Groups } \\
\text { numbers }\end{array}$} & \multirow{2}{*}{ Means } & \multirow{2}{*}{$\begin{array}{c}\text { Standard } \\
\text { deviation }\end{array}$} & $\mathrm{t}$ & $\mathrm{df}$ & $\mathrm{p}$ \\
\cline { 5 - 7 } & & & & $\mathrm{t}-$ test \\
\hline Experimental group & 80 & -29.81 & 5.29 & 11.09 & 188 & .000 \\
\hline Control group & 100 & .06 & 3.35 & & & \\
\hline
\end{tabular}

As $t$ absolute value calculated by degree of freedom of $188(t=11.09)$ is bigger than standard $t(t=1.980)$, so null hypothesis is not confirmed. So we conclude with $95 \%$ confidence that "average differences of both control and experiment groups in test of general health (total scale point) "is confirmed.

According to information gathered and because of significant differences between averages, we conclude that researcher's claim about "difference in the test of general health (total scale point) "is confirmed. Studies indicate that family and life skills training have significant effects on general health of influential family members (total scale point and all the sub tests of this scale). This difference in total scale point of pre- and post test of experiment group is significant but not in control group.

According to seventh hypothesis, "family and life skills training have effects on reducing family influential members' mental disorders." This hypothesis is examined in both experiment and control groups by SCl-90-R (table 7).

Table 7. T- Test Result in Independent Groups in Order to Comparing Meansin Experimental and Control Group in SCL-90-R Test

\begin{tabular}{|c|c|c|c|c|c|c|}
\hline Variables & \multirow{2}{*}{\begin{tabular}{c}
\multirow{2}{*}{ numbers } \\
Groups
\end{tabular}} & \multirow{2}{*}{ Means } & \multirow{2}{*}{$\begin{array}{c}\text { Standard } \\
\text { deviation }\end{array}$} & \multicolumn{4}{|c|}{$\mathrm{t}$ - test } \\
\cline { 5 - 7 } & & & $\mathrm{df}$ & $\mathrm{p}$ \\
\hline Experimental group & 80 & 59.57 & 13.89 & 11.015 & 188 & .000 \\
\hline Control group & 110 & 5.93 & 13.11 & & & \\
\hline
\end{tabular}


As $t$ absolute value calculated by degree of freedom of $188(t=11.015)$ is bigger than standard $\mathrm{t}(\mathrm{t}=1.980)$, so null hypothesis is not confirmed. So we conclude with $95 \%$ confidence that "average differences of both control and experiment groups in test of Symptom Checklist-90-Revised (SCL-90-R) (total scale point) "is confirmed.

According to information gathered and because of significant differences between averages, we conclude that researcher's claim about "difference in the test of Epidemiological mental disorders questionnaire (total scale point) "is confirmed. This difference in experiment group with respect to total scale point of Epidemiological mental disorders and its sub test (except for psychopathic sub test) is significant but not in control group.

\section{DISCUSSION}

Nowadays, societies encountered a fast and increasing development, such that we can name present era the age of unpredictable and accelerating transformations. For confronting threats and using possible opportunities for attaining organizational goals, organizations must identify their capacities and potentials and amend their weaknesses and strengthen their positions and in doing so, achieve quality and quantity development of their organization.

Studies indicate that family and life skill training to family members can be very influential in empowering society members and reducing social losses. It seems that traditional educational institutions such as family, school and other cultural institutions have not been successful in creating and developing such functions in family at present. Different factors such as mass media, different social and moral positions, social changes, different expectations and values of children and adolescents and their parents has created a great gap. So it is necessary that some opportunities be provided so that families and children and adolescents learn life skills in addition to reading, writing and mathematics abilities. With respect to above subjects, World Health Organization has provided a program entitled "life skills training" with the aim of promoting mental hygiene level and preventing social and mental losses(WHO, 2005).

As social and cultural factors determine exact nature of life skill programs, trainings may be different considering educational goal and content in different regions and countries. Training process is such that trainees involve in the subject of these skills actively. Training begins from knowledge acquiring and continues until its transformation to an attitude and its emergence as a behavior(WHO, 1996).

As mentioned in previous discussion, the main assumption is that family is a social system which has different influential mechanisms. Promoting family members' awareness level, changing their attitude toward mental disorders, incrising family members' social adjustment level and their self esteem specially their parents, promoting life skills, promoting family members' temperament and so on all can be influential in controlling and caring chronic mental disorders. 
(Dadji,1995; Rother,1999; cited by Pahlavan Zade et al.,1998)

The finding of present research based upon effect of family and life skills training on family members' attitude towards mental disorder in family are in line with researches of Campbell et al. (2006); Carver et al. (2004); Sanders \& Dadsy (1993 cited by Florsheim); Florsheim (2003); Teri (2002); MacCrath \& Braunstein (2007); Kata \& Joiner (2002); Elias (2007); Noori(2004); Moosavi Shooshtari (2006).

One of the other findings is that family and life skills training has significant effect on family members' attitude toward mental disorders in family. These results are different in control and experiment groups and indicates of significant difference of experiment group families ' attitude toward mental disorder in family. It seems that family and life skills training influences on family members' attitude toward mental disorders. This results are in line with the results of researches of WHO (2005); Touzandejani and Seddighi (2006); Khaiiati (1997); Kaplan \& Sadok (1997); Falsafi Nezhad (1993); Pahlavan Zade et al(1998); Goodstein \& Lanion (2005); MacCay \& Smith (2000); Lassiter (2005); Graham \& Cookril (2004); Johnsen \& Smith (2006).

Adjustment has a wide spectrum and includes dimensions such as family, peers, and society and above all is adjustment. It is believed if one have soial adjustment, wont has problem in other areas. From the old times researchers are seeking to know and control the factors which can manipulate this variable and factores such as training methods, peers' attitudes and beleifs, family and educational instituions have been more dominant.

Recently, some of the researchers have focused more on another factor of self esteem and consider it a very influential factor in creating and controlling adjustment behaviors and believe that those who have positive judgement and perception about themselves, will do less antisocial behavior and exhebit positive behavior more and this belief has been confirmed by many studies.

In general, findings of this research in the area of social adjustment and self esteem are in line with the findings of many researches cited in second chapter (e.g. Touzandejani \& Sedighi (2006); world health organization (2005); Mackie \& Smithe (2000); Lasiter (2005); Minuchine (1981); Kahn (1989); Campbellg et al (2006); Moosavi Shooshtari (2006); Falsafi Nezhad (1993).

It can be said that one of the reasons that collective methods of family and life skills training in the form of cognitive-behavioral are influential is their educational base. Because in this method both cognitive and behavioral aspects are emphasised. In this approach, individual's cognition about the problem is changed first and then they are trained in behavioral skills such as problem solving and so on in order to experience bavavior and cognition simultaneously.

Meanwhile for some training be influential more time is needed. Controlling other influential factors such as self esteem and subjects' previous social condition, controlling social and economic condition of families, marital style of families, social interaction of subjects with their peers, education patterns of teachers and social system of the families, controlling subjects' intelligent conditions and 
so on all can be influential in the efficacy of family and life skills trainings.

The findings of this study in the area of mental health and mental disorders are in line with many studies (e.g. Watckinze, 2002; Smithe, 2005; Baltone \& Ettelly, 2000; Jackson Edward, 2001; Platt, 2006; Raien et al., 2000; Stell et al., 2006; Waithback et al., 2007; Super, 2000; Frayeir, 1995; Arizi, 2003; Haghshenas, 1997; cited by Falsafi Nezhad,1993).

The findings of present study based upon the role of social support (family and life skill training) in reducing mental disorders and promoting family mental health are confirmed in various areas. Anxiety, stress, physical complaints, interpersonal sensitivities and so on are reported more in families with metal disorder patients. So findings of this study are in line with above mentioned studies.

\section{REFERENCES}

Campbell, J. D. Trophell., P. D.; lavalle, L. f.; Katz, I. M.; Heine, S. J. \& Lehman. D.R. (2006). Self-concept clarity: measurement, personality correlates and cultural 6 boundaries. Journal of Personality and Social Psychology, 70, 171-56.

Carver, P. R. \& Yunger,J. L. \& Perry, D. J. (2003). Gender identity and adjustment in middle childhood-sex Roles: A journal of Research 49, 95-109.

Derogates, LR. (1983). Sympton Checklist 90- R Administration, Scoring and Procedures manual- II. Towson, MD: Clinical Psychometric Research, 1415.

Elias, M. J. (2007). An action research approach to evaluation the impact of a social decision-making and problem-solving curriculum for preventing behavior and academic dysfunction in children. Evaluation and Program Planning 14, 397-407.

Florsheim, P. W. (2003). Family and cultural factors in the psychosocial adjustment of Chinese adolescent immigrantsJournal of Youth and Adolescence. 26(2): 43-63.

Falsafinezhad, M. R. (1993). The study of the self esteem effect on behavioral adjustment of students from 12 to18 ages with the class in Qum city. Tehran: Tarbiat Moallem University.

Goodstein, L. D. and Lanyon. R. I. (2005). Adjustment behavior and personality. Arizona state university.

Grahum, S. \& Cockriel, B. (2004) Indexes to assess social and personal development and the impact of college. College Student Journal, 30, 502-515.

Greenberg, G.Y. (2001). The effect of relationship enhancement program on marital communication and self-esteem. Journal of Applied Social Sciences, 5, 78- 94.

Jahnsen, J. W. \& Smith, E. R. (2006). Conceptualizing social identity.Anew framework and evidence for the impact of different dimensions.personality and social. Psychology Bulletin 25,120-135.

Kahn, R. H. (1989). The effect of a Group support intervention program on de- 
pression, social adjustment and self-esteem of adolescents in an overseas American international school. Washington DC: Nursing Science, Catholic University of America. P. 1859.

Katz, J., Joiner, T. E., Kwon. P(2002). Membership in a devalued social group and emotional well-being:developing a model of personal self-esteem. Collective self-esteem, and group socialization sex Roles: A journal of research. 47(419-431).

Khayyati, F. (1996). The study of self-esteem methods training effect to the mothers' boy and girls students for increasing children self-esteem. M.A. Thesis, Tehran: Tarbiat Moallem university.

Lassiter, E. (2005).An assessment of the relationship between student perception of school effectiveness and student achievement and social adjustment in zoned comprehensive public high schools. Baltimore, MD: Morgan State University. P. 1767.

Lynn, M. R.( 1996). Determination and quantification of content validity. Nursing research, 35: 382- 385.

Mackie, M. D. \& Smith, R. E. (2000). Social psychology (2 $2^{\text {nd }}$ ed.). Singapore: Psychology press.

McGrath, M. M. \& Braunstein, A. (2007). The prediction of Freshmen attrition of the importance of certain demographic. Academic financial and social factors. College Student Journal, 31, 396-908.

MoosaviShooshtari, M. (2006). Examining the relationship between family affective environment with personal social adjustment and academic performance of third grade secondary school in Ahvaz city. M.A. dissertation Ahvaz university

Noori, R. (2004). Life skills (critical and creative thinking, self awareness and empathy, confronting stress).Tehran ToiloeDanesh publication.

Pahlavanzade, S., Mehrabi, M., Ashoori, E.(1998). The study of the relationship between self- esteem and the family-individual characteristic in girl students of Isfahan high schools. Iranian Journal of Nursing and Midwifery Research. 4(9): 4-8.

Rosenberg, M. (1965). Society and the adolescent self-image. Princeton, NJ: Princeton University Press.

Schludermann,E.H., \& Schludermann, S.M.(2000). Adjustment Scale, Technical report. Winnipeg, M.B Department of Psychology, University of Manitoba.

Teri,R. (2002). Self-esteem and self-efficacy of college students with disabilities. College Student Journal. 36(2):214- 221.

Tozandehjani, H. \& Seddighi, K. (2006). Examining the efficiency cognitive and behavioral self esteem training on high school students social adjustment in Neishabour city. Academy research, research vice president in Neishabour Azad university

World. Health. Organization. (1996). Life skill training program. State social welfare organization, the prevention and affairs assistance. Geneva: WHO/ HQ: 1996. 
World. Health. Organization. (1999). Information series on school health. Violence prevention: an important element of a health- promoting school. Geneva: $\mathrm{WHO} / \mathrm{HQ}$.

Williams, P., Goldberg, D.P. \& Mari, J.(1987). The Validity of the General Health Questionnaire. Social Psychiatry, 21, 15. 